\title{
II.-THE RELATIONS OF ETHICS TO METAPHYSICS.
}

\author{
By W. H. Fairbrother.
}

THenr is a proverbial jibe at Philosophy as fruitless and unprogressive on the ground that it always asks the same questions and always patiently submits to receiving the same (contradictory) replies. Proverbs are however twoedged tools, and the truth undoubtedly contained in this familiar reproach might easily be shown to be very much to the credit of Philosophy, in a moral, as well as an intellectual, reference. In any case it may serve to justify the introdaction of the question discussed in this paper in the form given to it by Plato:-

This, my dear Glenoon, is the moment when everything is at stake with a man; and for this rasen, above all others, it is the duty of each of us diligently to investigate and study, to the neglect of every other subject, that science which may hoply ensble a man to learn and discover, who will render him so instructed as to be able to disariminate between a good and an evil life, and according to his means to choose; always and every where, that better life, by carefully calculating the intluences which the thinge just mentioned, in combination or in separation, have upon real excellence of life; and who will teach him to understand what evil or good is wrought by besuty tempered with poverty or wealth, and how the resplt il affected by the state of soul which enters into the combination; and what is the consequence of blending together such ingrediente as high or humble birth, private or public life, bodily strength or weaknese, readiness or slowness of apprehension, and everything else of the kind, whether naturally belonging to the soul or accidentally acquired by it; so es to be able to form a judgment from all these date combined, and, with an eye steadily fixed on the nature of the eoul, to choose between the good and the evil life, giving the name of evil to the life which will draw the soul into becoming more unjust, and the neme of good to the life which will lead it to become more just, and bidding farowall to every other conrideration. For we have seen that in life and in death it is best to ohoose thus.'

The immediate reference of these few lines from the tale of Er, the son of Armenius, is to thet critical moment when the souls who are to commence their new life on earth are

${ }^{1}$ Plato, Kep., 618 B, Davies and Vanghan's translation. 
about to choose their lots. The number of lots 'far outnumbered the souls that were present' and it was indeed all-important that the freedom of choice given should be exercised wisely. But the resl meaning of the passage has a much wider reference. In it Plato sums up his whole ieaching as to the nature of Morality, its relation to life, and the method by which our knowledge of it is to be attained. To him the one duty of the citizen as an intelligent being is, by 'diligent investigation,' to reach that comprehension of the true manner of life which alone could render possible the carrying it out in practice. No study $80 \mathrm{im}$ portant, or so indispensable, as this. None which could rightly claim from us such unwesried effort and such singleeyed devotion to truth, whithersoever she might lead. With this feeling of the absorbing importance of such knowledge went the conviction that its attainment was possible. Influenced possibly by carrent belief in Athens, certainly by the teaching of his master, Socrates, Plato held that the 'manner in which a man ought to live 'is in itself knowable and admits of intelligible exposition to others. From this it follows practically that men can be 'trained ' in it until they become able to exercise a wise self-control for themselves; and even if many men are incepable of attaining auch knowledge for themselves they can and should be guided by those who have that capacity. "Every one should be governed by a wise and divine power which ought, if possible, to be seated in the man's own heart," I but, in default, there is the alternative "to impose it from without". The Philosopher kings discharge that function in the body politic which his Reason ought to discharge in the individual man

Further, the attainment of this manner of life, in other words, of Excellence, or Virtue, is obviously only possible in the proper discharge of those functions which we are by nature fitted to perform. Introspective analysis is the manifest wethod of investigation to pursue in the search for such functions. It may be assumed-no Greek could question this Platonic assumption-that man is, 'by nature,' a social animal, a citızen. Th: Ethical question thus takes the shape 'What is fitting for a citizen to do?' To this question the only trustworthy answer is that which is deduced from the answer to the prior question 'What is a citizen?' $\mathrm{He}$ is 'manifestly a part of a complex whole, the well-buing of which, as of the parts themselves, depends solely upon the due discharge, by each part, of its proper function as

' liep., $590 \mathrm{D}$. 
such. He cannot 'live unto himself,' for this in every, except a purely physical, sense would be desth, not life. He must live ' in relation to ' his fellows, and these relations constitute the definite Moral Laws in accordance with which his life should be regulated. - To think otherwise, to attempt, e.g., to portray a life in which some individual citizen has all conceivable good things, whether appropriate to him or not, is as absurd as to lavish all the colours of the rainbow upon the eye in a marble statue. Such efforts are self-destructive, for true life, with its result, true happiness, is only realisable by each becoming the 'best possible workman at his own vocation'. Perfect morality is attained when the simple rule 'Let each do that which is his to do ' 18 completely carried out.

In this way we are necessarily taken back from theories of 'what ought to be' to the scientific investigation of 'that which is'. Our Ethics must be deduced from, and representative of, the truth of things. It 18 no use asking if we ought, or ought not, to pursue power, wesith, etc., until we have, by 'diligent study,' discovered what 'influence these ingredients have ' upon life itself. Such investigation revesls to us everywhere a Cosmos, an ordered whole, in the Society as in the Individual, in the Universe as in the Society. True reality (as revealed not by Sense but by Science) 18 a spiritual whole of interrelated parts. Man only becomes his true self in so far as he is, on the one side, such a microcosm in himself, and, on the other, discharges those functions which are binding upon him as part of the larger cosmos to which he is related. His highest excellence is to know reality and live according to it. In so doing he enters into the mind of God, the Creator, and becomes like unto Hiin. For only "by ever holding fast the upward road of right conduct gaided by understanding " ' can he hope to reach that ideal of "likeness to God" " in which his soul can find complete rest.

Virtue is thus seen to be the truth of things and brings with it necessarily life and happiness. Conversely, vice, as inconsistent with the laws of Nature, necesserily works out its own punishment. The man who sins is unavoidably doomed 'to suffer. The despot, the extreme type of wickedness, loses the power to live, in any human sense of the term, altogether; he parts with all freedom of action and becomes a veritable 'slave' to every momentary impalse, however degrading, unsatisfying, or maddening.

The questions thus raised by Plato, and the answers given,

$$
\text { 'Rep., } 621 \text { с. } \quad \text { Thwat., } 176 \text { в ; Rep., } 613 \text { А. }
$$


have been subject of controversy ever since. Nor is the hostility less uncompromising as time goes on. The representatives of the opposite schools are as antithetical in their antagronism to-day as were Plato and the 'Sophist' twentythree centures ago. The Platonic theory may be summed up in two propositions, (1) Ethical doctrine must be deduced or derived directly from the results of metaphysical investigation; (2) This deduction 18 possible; in other words, a science of human nature, in its environment, is so far attainable that we can lay down a theory of conduct which men 'ought' to try to realise in daily life. Both propositions are stoutly aftirmed, both with equal emphasis denied, to-day. On the one hand, writers such as Graham (in his. Creed of Scrence), Watson ${ }^{l}$ and T. H. Green remind us, as if it were a inere truism, that until " some definite conclusion in regard to the relation between man and nature is arrived at, no theory of Ethics is other than wasted labour"." On the other, Leslie Stephen (e.y.) assures us not only that the fulfilment of this condition is impossible, but that, luckily, the attempt to do so is both delusive and unnecessary. Ethics possesses at least one characteristic in common with the physical sciences, viz., that of giving us " knowledge which, within its own sphere, is entirely independent of the metaphysician's theories-the region of Science, ethical as well as other, 18 a region in which all metaphysical tenets are indifferent". "This last writer goes even farther and asserts, not only that Ethical Science is 'indifferent ' to metaphysical conclusions, but also that the two kinds of knowledge cannot be brought into connexion. " By the metaphysical method," he declares, "you cannot even approach the relevant questions of Ethics. ... In the metaphysical region you may come across ultimate canons of truth, but by no conceivable ungenuity upon principles of action." Finally, Prof. Sidgwick, inore suo, agreeing and disagreeing with both views, comforts us by saying, "there are certain absolute practical principles, the truth of which, when they are explicitly stated, is manifest; but they are of too abstract a nature to enable us to ascertain what we ought to do in any particular case; particular duties have still to be determined by some other method ". This verdict is apparently put forward as an effort towards reconciliation, but it would seem rather to accentuate the point at issue.

\footnotetext{
' Cf. Outl. of Phil., p. 189. "To act morally is to deternine oneself in accordance with the true nature of existence."

Prol. to Ethics, p. 54.

I Ibiil., p. 150.

3 Sc. of Ethics, p. 3.

Ateth. of Ethics, p. 378.
} 
It is important that we keep quite clearly in mind what this point at issue is. We are not concerned with the possibility of a Metaphysic, still less with the truth or the cogency of any particular metaphysical system. WVe are desling solely with the relation, positive or negative, between a thinker's ethical doctrine and his metaphysical belief. Some metaphysical position-explicit or implicit-a thinker must have. The choice lies solely between a good metaphysic and one not so good-between a carefully thought out body of doctrine on the one hand, and a more or less casual number of assumptions on the other. We may rail at Metaphysic as an " unearthly ballet of bloodless categones," "or regard it as " a barren region haunted by shadowy chimeras, mere spectres, which have not life enough in them even to be wrong, nonentities velled under dexterously woven masses of verbiage "; ${ }^{z}$ but some working ussumptions as to the ultimate truth of things we can as little do without as we can jump off our own shadow. Is it, or is it not, then, possible to separate these two departuents of thought, so that progress or change in the one way take place without effect upon the other "? The question uny be asked in two wrys-(1) Are the ethical doctrines taught by the more important wnters in this subject derived from, or traceable to, their respective metaphysical beliefs" or (2), in abstracto, is the subject matter of Moral Science of such a kind that it is necessarily affected by our belief as to the ultimate nature of man and the unjverse?

The philosopher 18 tempted, naturally, to attack the question in the latter form, nor is it disputable that, should success follow the effort, the result must be more finally satisfactory than any mere historical review, however accurate and complete, can attain to. Unfortunately, it is difficult to treat the matter in this way without petitro principul and, in any case, it is, perhaps, the more hopeful course to stick closely to the facts of philosophical history, at least in the first instance, rather than to theorise entirely in the abstract.

A review, in detail, of the doctrines of even the more 1mportant ethical writers opens up a prospect, the length of which may cause a shudder; but, fortunately, it is only necessary, for the present purpose, to deal with one or two typical expositors. By confining ourselves, further, to the best known of these, we avoid the necessity of any detailed statement of their respective views and are able to fix our

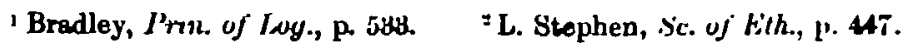


attention solely upon certain relevant features. Such selection must be, necessarily, more or less arbitrary, bat that does not matter provided it be representative.

In the first place, then, it 18 obvious that a great body of thinkers (of whom Plato in the ancient world, Green in modern times, Prof. Watson among the present generation, are typical) do, as a fact, base their moral teaching directly and, as far as possible, deductively upon the results of their metaphysical investigations. It is needless to labour this point. Further, it will be admitted that to a certain extent (how far exactly is matter of controversy) such deduction carries us past the domain of abstract principle into that of a definite moral code, applicable to the msin problems of civilised, or other social, life. It may, or may not, be true that (in Prof. Sidgwick's words ${ }^{1}$ ) " while there is much instructive description and discussion of the general attitude which a moral man should adopt in dealing with practical problems, there is no cogently reasoned solution of any such problems, proceeding from unambiguous ethical premises to definite practical conclusions," but it is at least indisputable that with these thinkers ethical doctrine, in both principle and concrete detail, stands or falls with their conclusions as to the 'truth of things'.

On the other hand it is equally obvious that many writers, in popular estimate, reach their ethical results by other roods than the metaphysical. Kant, Spencer, Mill, seem to possess at least this negative characternstic in common, and the investigations of the English Moralists of the eighteenth century appear equally free from the taint of Metsphysics. It will be better to consider the former individually, but the latter, for the present reference, may be taken collectively. Of them, in the main, the popular estimate may be admitted to hold good, but it can hardly be accepted, without important reservations, in regard to the former.

First Kant. Nothing could, at first sught, seem clearer than the separation of the Kantian ethics from the Kantian metaphysica. The one takes as fundamental postulate certain things the existence of which the other asserts stoutly to be unknowable. A deeper investigation, however, seems to show that this independence is merely superficial; the moral teaching is really an integral portiou of a philosophical whole, each part of whioh is indispensable to the other. Kant's Lehre may be stated shortly as follows :-

An examination of the process of human knowledge reveals

1 MInd, April, $18 \% 4$. 
to us at once its necessary limit and gives us the conception of a higher systematic unity of which scientific cognition forms merely an integral part. ${ }^{1}$ Scientific cognition consists of a certain matter of experience, which is received from without, but only under the conditions of self-conscionsness, the laws of which prescribe the form under which the empirical world is presented. Hence the limit of such knowledge is the limit of possible intuition, and the knowledge itself is conditioned throughout by the forms of the Understanding. It gives us merely a ' contingent aggregate '.'

Reason however demands not a contingent aggregate but a connected organuc whole The Categories cannot give us this. Their highest conception is that of $\backslash$ natural causetion in the world of sense experience-phenomena-and we require a causality which is, not conditioned, but unconditioned. The unity and the causality appearing in cognition are but the shadows of a higher unity and an unconditioned causality which cen only come from Resson and which form Reason's necessary law. Have we any evidence of the actual existence of such a causality?

Yes. We have given in consciousness a fact of such a nature that its content is not limited by the conditions of intuition, and is inexplicable except through the supposition of Freedom, ciz., the Moral Law, or Duty, which is pure form and unconditioned, and can, therefore, be given only by Reason to Reason.

This 'freedom' is no arbitrary freedom; it is a definite kind of causality, working by Law. Its law is the antonomy of the will-a free will and a will subject to moral law are one and the same.

Now man belongs both to this noumenal world and to the phenomenal world. Hence arises Moral Obligation. The law of his Reason-Freedom-is a law of that real world which 18 the very foundation of that phenomenal world in which he lives, and is therefore operative in it and binding upon him. In the domain of the Practical Reason, then, we come into contact with noumensl reality and find that cansality, that systematic unity, which the Categories of the Understsnding cannot give us-find both ourselves, and God.

These ideas-God, Freedoin, Immortality-do not admit of either demonstration or comprehension (otherwise they would be necessarily conditioned), but on the other hand

\footnotetext{
'This case for the ' lnity' of Kant is practically only a summary of the lengthy argument of Prof. Adamson in his Philosophy of Knnt.

Cf. Adamson, p. 75 .
} 
they are not arbitrary essumptions. They are necessary assumptions in the domain of Reason itself, and could only be rejected on the (obviously untenable) ground that they contradict the results of the speculative employment of the same faculty. Nor again is there any radical difference between pure practical and pure speculative Resson. They are both equally Reason and the same Reason, which as self-determining supplies us with notions of Freedom, as determined with notions of Nature, the Categories of the Understanding. ${ }^{1}$

If the above summary be correct the complete interdependence of the Kantian Ethics and the Kantian Metaphysics is obvious. On the other hand it can hardly be denied that he is wanting in the successful deduction, from these fundamental conceptions, of that detailed code of action which Prof. Sidgwick holds it 18 the sole function of Ethics to give us. In this respect Mr. Herbert Spencer and J. S. Mill, while teaching an ethical doctrine equally due to their respective metaphysicsl positions, sre much less open to criticism.

Herbert Spencer. Mr. Spencer is sometimes spoken of as an Agnostic, a charge to which his use of the word ' anknowable "lends an occasionsl plausibility. But this unknowability refers solely to the conception, in its completeness, of the Ultimate First Cause of things. Omniscience, he holds, 18 beyond our reach, but scientific cognition of phenomena, so complete that it reduces the spparently bewildenng chros of experiences to an intelligible principle, is not beyond our analytic copacity. Reality, in all its fulness of detail, is due to the fact that

A Power of which the nature remains for ever inconceivable, and to which no lunits in Time or Space can be imagned, works in us certain effects. . . . Analyeis reduces these several kinds of effect to one kind of effect; and these several kunds of uniformity to one kind of uniformity. And the highest achievement of Science is the interpretation of all orders of phenomens, as differently conditioned manifestations of this one kind of offect, under differently conditioned modes of this one kind of unilormity."

Ethical phenomena form one portion of the sum total of phenomens to be so explained. The direct dependence of such phenomens upon the nature of Reslity, and the unsatisfactoriness of any attempt to arrive at Moral Laws, except by deduction from metaphysical truth, are stated in the clearest language by Mr. Bpencer :-

${ }^{1}$ Cf. Adawson, p. 126.

${ }^{3}$ First Principles p. 667. 
T'he view for which I contend is, that Morality properly so calledthe Bcience of right conduct-has for its object to determine how and why certain modes of conduct are detrimental and certain other modes beneficial. These good and bad results cannot be accidental, bat must be necessary consequences of the constitution of things: and I conceivg it to be the business of Moral Science to deduce. from the laws of life and the conditions of existence, what kinds of ection necessarily tend to produce heppiness, and what kinds to produce unhappiness. Having done this, its deductions are to be recognised as lews of conduct.

In other words, the ancient doctrine that Morality is in the nature of things-that 'morally right' is identical with that which is 'naturally fitting'-forms the backbone of Mr. Spencer's teaching. For him, as for Plato, the moral Idesl will be attained when the moral conduct has become the natural conduct, and ethical guidance must be sought in the laws which analysis of man's place in natare reveals to us. The conception of nature, however, in the mind of the nodern thinker, hss lost the simplicity which it possessed in early philosophy. Nature is still a cosmos, an interrelated whole; perfection is still conceived as an equilibrium produced by proper performance of function by each part, but the equilibrium 18 no longer a definite state which, once reached, is to last for ever, and in which any change is, ipso facto, for the worse. The equilibrium is a moving one. Progress consists not only in the tendency towards a state of harmonious balance of forces, but also in the movement towards higher stages of these successive 'rhythmic' wholes. To the Greek thinker human nature, or at least the only kind of human nature he held it worth while to think about, was a fairly complete thing which required to take (so to speak) bat a short step in the direction of more thoughtfal self-control in order to reach that highest level we call the complete or perfect life. To Mr. Spencer life at any stage is but a passing phase in an evolution whose origin is lost in an unfathomable past and the final perfection of which is hidden in an unknowable future. The difference for ethical inquiry, thus arising, is fundamental. The modern thinker still asks the old question, 'What ought men to do?' bat the import of this question has materially changed. Man 18 no longer merely a fellow-citizen, like unto ourselves, with wants, impulses, ressoning powers and idesls, identical with our own, and definitely intelligible. He comes clothed with an involved history which must be investigated before ethical problems can be even stated, and pointing to a far distant fature to wait for before these problems can be solved. He is a link in a chain, the whole of which must, in some sense, be brought

'Data of Ethics, ch. 4. 
into our field of view before we can hope to understand any part of it. We have to examine what man has been doing in the past, and not only what he has been doing but what the rest of nature has been doing as well. "Fully to understand hurnan conduct as a whole, we must study it as part of that larger whole constituted by the conduct of animate beings in general," " which can only itself be understood by examining it in the successive stages of its development. The history of man becomes all-important. This history is inextricably interwoven with that of natare as a whole, and cannot be fully understood until the evolution is complete.

The ethical problem has thus become wider, and infinitely more difficult, but is not so hopeless as this statement of it would seem to imply. The history to be investigated is an intelligible history. It is that of a continuous evolution exhibiting unity of plan and revealing, throughout the successive stages, the fundamental laws of its development. One great law, more especislly, manifests itself throughout the, at first sight, bewldering complexity of these changes, and gives ns an unfailing clue through the labyrinth of the world's history. This law may be stated as follows: "Nature has progressed. and is progressing, from an indefinite incoherent homogeneity to a definite coherent heterogeneity". " This law is aniversal and all-pervading. It reveals itself in both the matter of the universe and in the motions of that matter. It 19 as obvious in the interrelations of conduct as it is in the constitution of physical reality. With it as a clue we are enabled to see clearly the past, to understand the present, to enticipate the future.

We can now see the inadequacy of the Greek conception of the ethical problem. Man is dynamic, not static. Morality is itself a progress which is essentially related to that of the rest of existence. There is " an entire correspondence between moral evolntion and evolution as physically defined ". 3 The two advance together and mutually imply one snother. It would be impossible for the 'moral' man, i.e., the man in whom the moving equilibrium is perfect, to exist in an incon. nruons environment. "The production of the highest type of man can go on only part passit with the production of the highest type of society," " which is, again, impossible apart from the existence of fitting surroundings, Complete moral evolution involves complete physical evolution. The perfect inan implies not only a perfect society, but also an ideal world.
1 Rata of Eth., p. 7.
7 Ibid, p. 6.5.
Ibid, p. 74.
' Jbid, p. 73. 
On the other hand it is obvious that this ideal whole contains many elements which do not properly fall under the Science of Ethics. Moral Science deals only with conduct, i.e., with the adjustment of acts to ends, and must limit itself to a comparatively small portion of even this field. The part of conduct it investigates is that alone upon which ethical judgments are passed. It is true that the components of moral conduct are inextricably bound up with the rest of condact, and that the latter passes into the former by small degrees and in countless ways, but it is none the less true that by far the largest portion of conduct falls outside the sphere of Ethics. It is also true, and even more important to remember, that the same condact, i.e., the same concrete act, may be sometimes moral, at other times not. Fthics, that is to say, is limited to the consideration not only of it certsin part of conduct, but, further, to a definite aspect of it. "Ethics hes for its subject-matter, that form which unıversal conduct assumes during the last stages of its evolution as displayed by the highest type of being." 1

If, finslly, the inquirer, feeling a little puzzled, if not donbtful, suggests that Ethics deals not with ' highly evolved' but with 'good' conduct, a little reflexion will show hun that the two terms are equivalent. Evolution consists in the more complete adjustment of acts to ends, and the term 'good' is the term universally chosen to signify the recognition of such sdjustment in all three kinds of acts-self-preserving, offspring-preserving, society-preserving.

This sketch of Mr. Spencer's doctrine, stated as far as possible in his own words, reveals clearly the fact that his theory of what 'ought to be done' rests throughout upon his analysis of 'that which exists'. How far he is anccessful in deducing therefrom a concrete code must remain, perhaps, a matter of opinion, but it should be noted, under this reference, that his chief aim is to show 'how and why' certain conduct is right and other conduct wrong. His Ethics, consequently, becomes inextricably interwoven with his metephysics. The popular notion to the contrary seems to have arisen from an accident of language. Mr. Spencer is so anxious to avoid the Bcylla of 'Intuitionalism' that he falls into the Charybdis of 'Utilitarianism'. Metsphor apart, influenced by the opposition (in its crudest form) of a priori or a posteriori knowledge, and rejecting the former as anresl, he deliberately adopts the language of sensationalism even when he is basing most distinctly his results upon scientific

${ }^{1}$ Data of Eth., p. 20. 
reasoning. Hence, though no condemnation of the Utilitarian test-a feeling of pleasure-can be clearer or more emphatic than his, he yet constantly uses Utilitarian phraseology. Btrictly speaking, the opposition between the Evolntionary Hedonism of Mr. Spencer and the Utilitarianism of J. B. Mill is antithetical-the latter holds that an act is right becsuse it gives plessure, the former that it gives pleasure becsuse it is right-but the verbal form in which $\mathrm{Mr}$. Spencer frequently clothes his teaching hides this fundamental difference from the superficial reader.

J. S. Mill. To give, even summarily, a statement of Mill's - ethical doctrine is, fortunately, needless. His Utilitarianiom is probsbly the most widely known of all moral treatises; a fact due partly to the practical commonsense tone of the book, but, perhaps, even more to the beauty of the concrete ideal therein pat before us.

Mill, however, is clearly conscious that the claims of even Utilitarian Morality to our allegiance must rest upon a surer basis than that of attractiveness. Having explained clearly what Utilitananism means he proceeds to show that theoretically it admits of as cogent justification ss any other system, and that its end is the only practical aim which men, as rational crestures, do or can set themselves to realise.

His method of proof is bsed directly and explicitly apon his general philosophical position. Rejecting, as untensble assumption, any intuitional theory of the origin of the Moral Sentiments, he maintains that rules of conduct are derived from, and can only be justified by, the facts of experience. He appesls solely to the snslysis of hamsn nature. His way of viewing homan natare is, on the other hand, very different from that adopted by, e.g., Plato, and is equally at variance from that of a Hedonist such as Mr. Spencer. Mill hss no conception of sny épyov rov ávipárrov, of snything which analyeis of human faculties reveals as 'fitting' for man to perform. He makes no reference to man as part or member of any organic whole, whether cosmic or civic ; still less does be accept the doctrine that the moral code should be deduced from those functions which men, as integral parts of such a whole, are intended 'by Nature' to discharge. Historical or evolutionary considerations, again, enter into his method of investigstion as little ss the conception of the social organism. Men are looked at, so to speak, so they stand, not regarded as links in a chain of progressive development. The present is in no sense a product of the past; at least, no attempt is made to explain the present by the past, or to discover rales for conduct by investigation into ante- 
cedent social stages. That ' race experience' may, by growth and accumulation, gradually alter the physiological and psychological constitution of man in such wise as to seriously affect, if not totally account for, his attitude towards social and moral questions, is a conception entirely foreign to Mill's system of Ethics. It might almost be said, indeed, that man finds no place at all in this system, but only men. Average human beings regarded as an aggregate, and interrogated separately and individually, form the sole source from which we may obtain insight into ethical truth. We must not ask what men ought, normally, to do or feel towards each other as parts of a social organism, but what, examined individually one after another, they as a matter of fact do feel and perform. Just as, in the physical world, the proof that an object is visible or andible is obtained from the fact that men see or hear it, so in morals the only possible demonstration that an end should be desired or aimed at lies in the fact that men actually desire or aim at it.

The final result of this empirical observation of our fellowcreatures (including one's own self) is to establish three things :-

(1) That as a fact men do desire nothing but happiness.

(2) That this happiness = the general happiness, or at least includes that of some other individuals.

(3) That the term happiness is not an empty, rague abstraction, but has a definite concrete meaning, intelligible to the plain man, and practically effective upon conduct.

To enter in to the detailed ressoning by which Mill seeks to establish these fundamental points would take us too far from our main subject. I will quote only one short passage, by way of illustrating and emphasising his method. The immediate reference of the extract is to point No. (1):-

If it be psychologically true that haman nature is so constituted as to desure nothing which is not either a part of happiness or a means of happiness, we can have no other proof, and we require no other, that these are the only things desirable. If so, happiness is the sole end of hrman action, and the promotion of it the test by which to judge of all human condnct; from whence it necessanly follows that it nust be the criterion of morality, since a part is included in the whole. Now to decide whether this is really 80 ... we have evidently arrived at a question of fact end experience, dependent, like all similar questions, upon evidence. It can only be determined by practised relf-conscionsness and self-observation, asisted by observation of others. I believe that these sources of evidence, impartially consulted, will declare that . . . to desire anything, except in proportion as the idea of it is pleasant, is a phyaical and metaphysical impossibility. ${ }^{1}$

1 Utilit., p. 38. 
Historical evidence, so far, has been all in one direction, but it must be frankly admitted, on the other hand, that of the English eighteenth century Moralists, speaking brosdly, the fact holds, that no metaphysical theories, no ideas as to the ultimate (or even proximate) truth of things, form the basis of their moral teaching. In this 'age of facile individuslism,' as it hes been called, ${ }^{1}$ sttention seems to hsve been concentrated solely upon the fact that men everywhere exhibit feelings of moral approval or disepproval Upon this fact the method of introspective analysis was brought to bear in the attempt to answer two questions, (1) How many different moral gentiments do actually exist? (2) Is their origin to be sought in Feeling or in Resson? The 'Resen,' however, to which Morality was by certain thinkers attributed was conceived as a peculiar, separate, moral Faculty, obeying its own laws, not to be identified with Reason in the ordinary sense, or held liable to the difficulties connected with epistemological speculations. Even if we adopt the late Prof. Wallace's" kindly estimate, vix., "these separate Moral Faculty theories really rest upon the belief that moral good and evil are not arbitrary or esotenc distinctions, bat rest upon a common and permanent element of human nature, and that, therefore, this fundamental natare, common to all men, must be able to detect their existence," even so, this belief remsins an unproven assumption, unsupported by any reasoned scientific justification. The psychological analysis may be true, as far as it goes, but its journey is so very short that it hardly seems worth while to have started at all.

Are we to say, then, that Ethics is independent of metaphysics only in so far as it is valueless even as Ethics? Such answer is temptingly easy, nor can it be denied that the review we have just finished lends considerable plausibility to it. Considered in abstracto, agsin, the arguinent in its favour is irresistible. Ethics is indisputably a theory of the proper conduct of life. Bome theory of life is therefore necessitated. No theory of life can be based (rationally) upon anything else than an examination into the nature of man and its relation to its environment, in other words, into the nature of reslity. Conversely, Sophistry destroys Ethics by simply taking a way our belief in a rational, i.e., coherent or intelligible, Reality.

Is there, then, nothing in the contention of that school of thought which, for the sake of simplicity, I have identified with

'By Selby-Bigge in his British Moralists, p. Ix.

'In his Inaugnral Lecture at Oxford, 7th Dec, 1682 
the names of Prof. Sidgwick and Mr. Leslie Stephen? Far from it-there is great trath in their contention bat (if I may gay so without offence) they have expressed it badly. The object of this paper is not to champion one side or the other, but to do something towards that useful - albeit ungrateful-task of enabling each side better to understand one another. When it is maintained that Ethics is independent of Metaphysics what is really meant is thet in this year of our Lord 1903 our knowledge of Reality is not complete enough to enable us to deductively demonstrate the multifarious detail to which answers must be given, and practically acted upon, in daily life. It is a fact, undeniable except by a fanatic, that every moral code must contain elements which are due to the necessity of answering, somehow, questions, the final solution of which lies in a far distant future. It is also a fact that a code containing none but elements of this haphazard kind cannot maintain its hold upon us for a day. Our theory of what ought to be is necessarily to be brought into co-ordination with our doctrine of that which is, but the co-ordination is not yet complete. Whether we lay emphasis upon the one aspect or the other is an accident of temperament. If our interest lies in the how and why, re gaze with astonishment at men who try to aggregate together rules of life from the shallow superficialities of daily experience, without any attempt to integrate these rules into a coherent whole. If our sole desire is to possess working rules we wonder how any man can busy himself with nnprofitable abstractions instead of investigating the actual facts. That this latter is the real meaning of the dislike to any metaphysical system of Ethics, the quotstion of a few phrases will sufficiently show. Green, e.g., is 'instructive,' but gives us "no cogently ressoned solution of definite practical problems"1-a "method of Ethics means any rational procedure by which we determine Right Conduct or Practice in any particular case " 2- "currently accepted principles are wanting in clearness and precision, they do not tell us e.g. whether primogeniture is just, ... yet such questions as these are those to which we naturally expect answers from the moralist. For we study Ethics. for the sake of practice; and in practice we are concerned with particulars." "As we assign the relations between parts of space without asking what is apace in itself, msy we not determine rales sbout men without asking what is meant o.g. by personal unity ? . . " "My view is that the Bcience

1 Bidgwiak, Mlord, April, 1884.

'Ibid, p. 813.
Bidgwak, Weth of Eth, p. 1.

- L. Btephen, Sc. of Eth, p. 2 
of Ethics desls with realities; that metaphysical speculation does not help us to ascertain the relevant facts; and therefore that it has no more relation to Ethical Science than to any other branch of knowledge." 1 It would surely be nearer the trath to alter this phrase 'no more than' into 'just 80 much as'. Men were tried and sentenced in law courts before the sciences were sufficiently integrated to enable us to apply the truths of Forensic Medicine, but that this should be so was merely a temporary necessity. It is equally a temporary necessity that we have to lay down relations between man and man without the help which a complete understanding of personal unity would afford. TVe may emphasise at our pleasure (it 18 mannly, as I have said, an accident of temperament) either the word Ethical or the word code, but let us not convert a variation of emphasis into a difference in kınd. The subject-matter of Ethies is as much an integral portion of the resl world as that of any other Science. The integration of knowledge is unfortunately not yet so complete as that of the Reality we seek to know, but nothing can be gained by treating passing difficulties as insuperable obstacles. The dim perception of Reality as a coherent whole was the beginning of science-the clear vision of this whole in complete detail is the goal at which it aims. To believe otherwise is to commit intellectual suicide-to urge such belief upon others is to be gailty of treason towards humenity.

' L. Stephen, Sc. of Eth., p. 480. 